\title{
A comparison of advanced thermal cycles suitable for upgrading existing power plant
}

$\underline{\text { G. Heyen }}^{1}$, B. Kalitventzeff 1, 2

1 : Laboratoire d'Analyse et Synthèse des Systèmes Chimiques, Université de Liège, Sart Tilman B6A,

B-4000 Liège (Belgium), tel +32 4 3663521, FAX +32 4 3663525, email G.Heyen@ulg.ac.be

2 : BELSIM s.a., Allée des Noisetiers, 1, B-4031 Angleur (Belgium)

\section{Scope}

In view of the constant growth of electricity usage and public pressure to reduce the dependence on nuclear power plants in the energy supply, solutions are sought to increase the capacity of power plants using fossil fuels. Highly efficient cycles are available : gas turbines combined with waste heat boilers and steam cycles are able to achieve efficiencies above 50$55 \%$. However building new plants requires a large amount of capital.

Alternative proposals are based on upgrades of existing plants : capital savings are expected by reusing part of the facilities. In the present study, three parallel proposals are compared on the basis of exergy efficiency; cost of investment and flexibility of operation are also discussed. They are compared with classical Rankine cycle and state of the art combined cycles.

\section{Reference cycle}

In order to provide a uniform framework for all subsequent comparisons, a somewhat simplified model of a classical power generation cycle has been first developed using BELSIM-SIMU simulation software (Belsim 1995). The reference is a Rankine cycle with steam reheat and water preheating using extracted steam, and is illustrated in figure 1.

Fuel is natural gas $\left(84 \% \mathrm{CH}_{4}, 11.9 \% \mathrm{C}_{2} \mathrm{H}_{6}, 3.5 \% \mathrm{~N}_{2}, 0.6 \% \mathrm{CO}_{2}\right)$ available at 35 bar. Superheated steam is produced at $810 \mathrm{~K}, 180$ bar. After first expansion, a part of it (approx. $20 \%$ ) is extracted to preheat boiler feed water, and the rest is reheated to $808 \mathrm{~K}$. After a second expansion to 5.5 bar, some more steam is extracted to heat the feed drum. A third extraction occurs after expansion to 0.8 bar. The condenser nominal pressure is 0.065 bar.

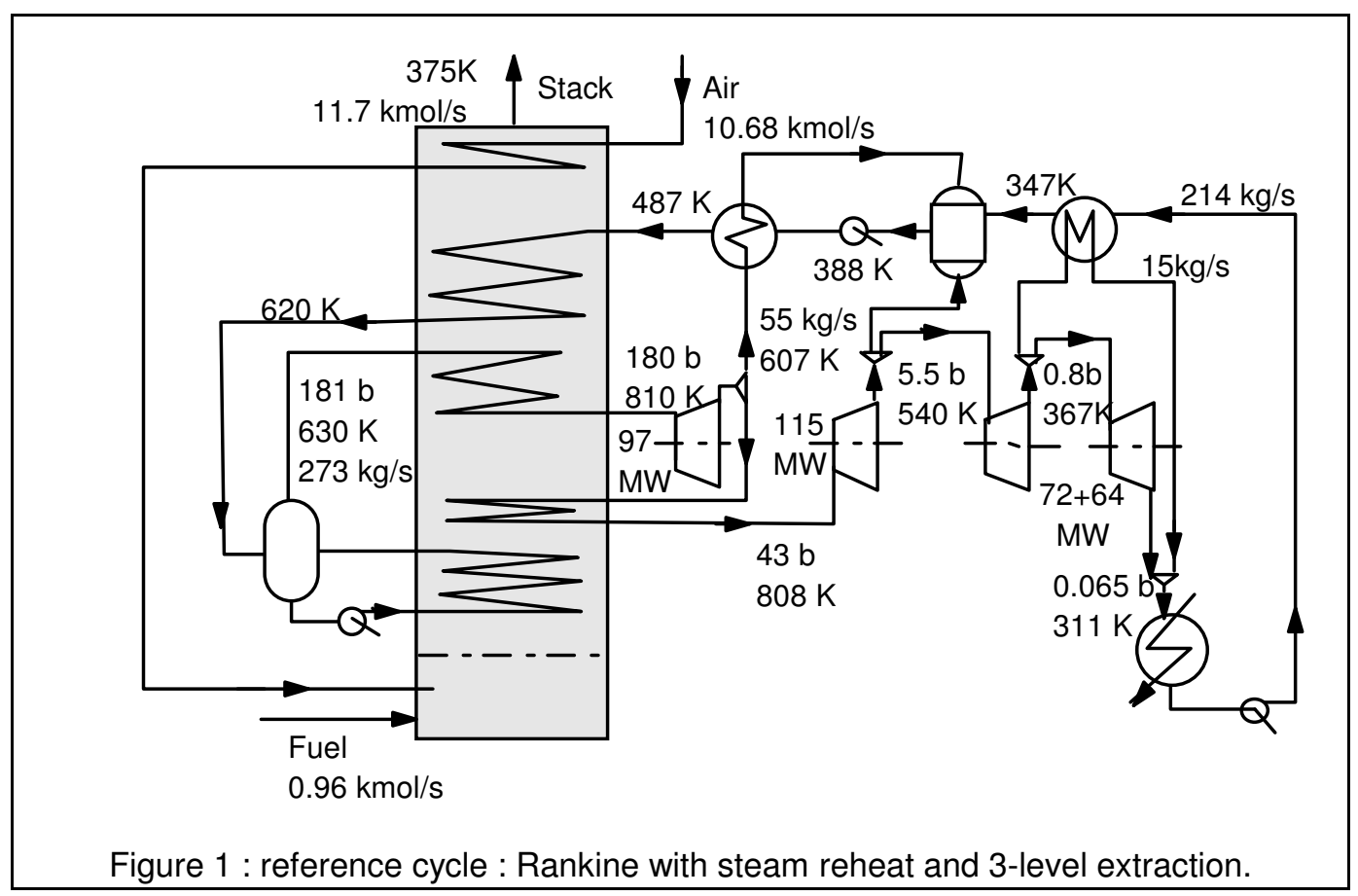

Applied Thermal Engineering MS 768
A comparison of advanced thermal cycles suitable for upgrading existing power plants 
The superheated steam flow rate is $272.6 \mathrm{~kg} / \mathrm{s}$, and the condensate flow rate is reduced to $214 \mathrm{~kg} / \mathrm{s}$ due to intermediate extractions. Air flow rate is $10.67 \mathrm{kmol} / \mathrm{s}$ (excess air is $10 \%$ ), fuel gas usage is $0.96 \mathrm{kmol} / \mathrm{s}$, and fumes production is $11.69 \mathrm{kmol} / \mathrm{s}(324.4 \mathrm{~kg} / \mathrm{s})$.

Net power generated is $340 \mathrm{MW}$ (HP : 96.6, IP : 115, LP : 71.6+63.7, power needed to drive pumps is $7.1 \mathrm{MW}$ ), thus calculated thermal efficiency is $41.9 \%$, and exergy efficiency is $40 \%$. In all the models used in this study, heat losses to the environment, mechanical and transformation losses have been neglected.

Even if some simplifications have been introduced in the model (namely the number of extraction stages is usually larger), such a cycle is representative of currently operating plants.

\section{Repowering an existing system}

Improvements of steam and gas turbine technology lead to some economical potential in capacity and efficiency increase of existing power plants. Depending on age, size and configuration of the existing plant, a number of rehabilitation concepts can be compared. The simplest way to increase the power of an existing plant is to install additional generators and prime movers in parallel to the existing equipment. With respect to a grass root construction, some savings can be expected by reusing part of the older facilities, in case spare reserves are available (e.g. workshops, water treatment, administrative buildings, roads, fuel storage).

Combining a steam and a gas cycle is known to improve considerably the efficiency of work production, and many combined cycle plants have recently been put in operation. However the conversion of existing large steam power plants with reheat to combined cycle power plants is a rather new concept. (Kotschenreuther 1994)

In the following, one will evaluate the potential for a capacity increase in the order of $15-20 \%$ of the existing Rankine cycle.

\section{Additional gas turbine}

Installing a gas turbine coupled with a generator is a relatively low investment cost solution. Aeroderivative turbines are available in a range of power, and allow flexible operation (short start-up time). However their efficiency is low, since most of the fuel energy is lost in the stack gas. Due to the limitation of blade temperature, gas turbines are operated with a large air excess. A typical engine with $1190^{\circ} \mathrm{C}$ turbine inlet temperature and a compression ratio equal to 23.2 delivers $25.6 \mathrm{MW}$ using $0.088 \mathrm{kmol} / \mathrm{s}$ fuel gas. The exergy efficiency is only $33 \%$, and heat rejected in the flue gas accounts for a significant part of the losses. Exhaust gas is hot $\left(434^{\circ} \mathrm{C}\right)$, available in large quantity $(3.44 \mathrm{kmol} / \mathrm{s}=98 \mathrm{~kg} / \mathrm{s})$ and contains a significant amount of oxygen $(15 \%)$. Several techniques that have been devised to improve the efficiency of gas turbine cycles are discussed here below. With such a low efficiency, gas turbines are seldom used to provide the base load on the grid : they tend to be limited to peak shaving operation, where their flexibility is appreciated.

\section{Combined cycle}

A waste heat boiler can be designed to recover efficiently the energy in the exhaust of a gas turbine. The flowsheet of a typical combined cycle plant is presented on figure 2. Since the hot gas temperature $\left(550^{\circ} \mathrm{C}\right)$ is much lower than the temperature in the combustion chamber of a fired steam generator (above $1500^{\circ} \mathrm{C}$ ), matching the cooling curve of the gas with the heating curve of water and steam requires a complex design. Production of steam at several pressure levels ( 2 and even 3 in recent designs) is needed for enhanced heat recovery. Extended heat transfer area is needed to compensate for the lower temperature difference (less than $10^{\circ} \mathrm{C}$ at pinch points) and for the absence of radiative transfer.

Applied Thermal Engineering MS 768
A comparison of advanced thermal cycles suitable for upgrading existing power plants
Page 2 
Due to the clever arrangement of the heat recovery system, combined cycles can achieve a good efficiency and be used for base load production. Heavy duty gas turbines used in these applications differ from aeroderivative lightweight machines, and deliver up to 150-200 MW. For the cycle illustrated in figure 2, gas flow rate is $0.527 \mathrm{kmol} / \mathrm{s}$, air flow rate $17.2 \mathrm{kmol} / \mathrm{s}$ (air excess is $338 \%$ to limit turbine inlet temperature), and fumes production is $17.8 \mathrm{kmol} / \mathrm{s}$ $(505 \mathrm{~kg} / \mathrm{s})$. Stack temperature is below $100^{\circ} \mathrm{C}$. The net power production is $235 \mathrm{MW}$, and overall cycle exergy efficiency is $50.6 \%$, compared to $31.0 \%$ for the gas turbine alone.

Such a high efficiency requires large waste heat boilers specifically designed, and the investment is significant (approximately $700 \mathrm{kECU} / \mathrm{MW}$, including cooling towers and environment protection (noise reduction, emission control, etc.). Thus such a scheme cannot be proposed to debottleneck an existing facility.

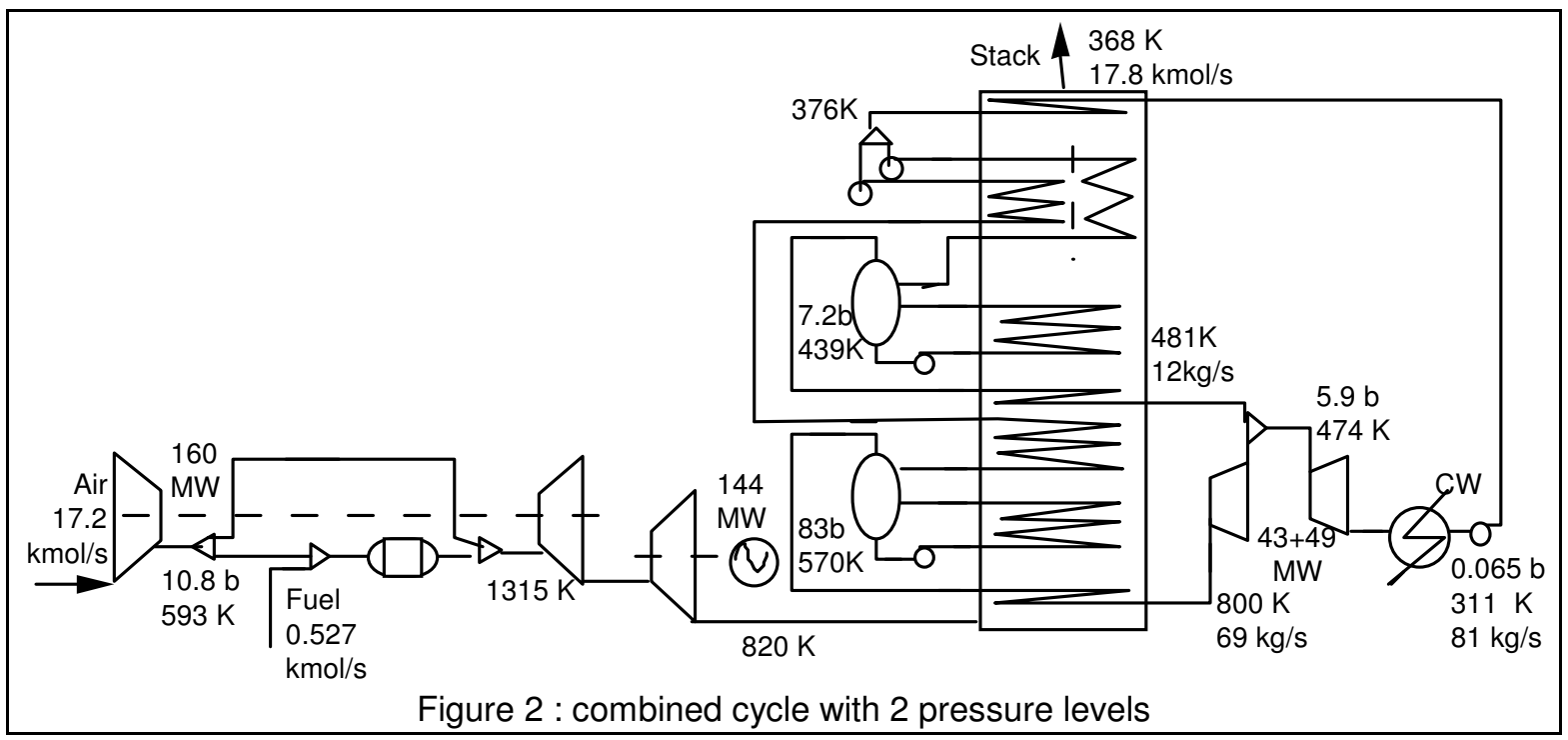

\section{Repowering a Rankine cycle by topping with a gas turbine}

In view of such a high efficiency, one may wonder whether the adjunction of a gas turbine to an existing power plant would improve the efficiency and the throughput of the cycle. One should note however that such a modification will induce many changes in the process operating conditions.

The exhaust of the gas turbine still contains a large amount of oxygen and its temperature is relatively high : the machine, while generating additional shaft power, may also be viewed as an air preheater. However the practical implementation of such a scheme implies significant modification of the boiler steam generator and water circuits, as shown on figure 3. The existing air preheater can no longer be used, since the gas turbine already delivers oxidising gas at a temperature higher than the classical air preheater. Removing the air preheater from the flue gas channel would result in a large increase of the stack temperature (since a low temperature heat sink disappears). Such a waste of energy can be avoided by heating a cold stream, such as boiler feed water. In fact, the duty of the air preheater corresponds roughly to $2 / 3$ of the enthalpy needed to raise the condensates to the inlet temperature of the economiser. However this means that the amount of steam extracted from the turbines for such a usage is to be reduced. The total steam bleed flow rate corresponds approximately to $25 \%$ of the boiler production. Reducing the bleeds will thus put the turbine line out of balance, since the LP turbine and condenser are not likely to be able to accept a $33 \%$ increase of capacity. Thus the inlet flow rate of the turboset, and thus the power generated by the original machines will decrease; in the following study, calculations have

Applied Thermal Engineering MS 768
A comparison of advanced thermal cycles suitable for upgrading existing power plants
Page 3 


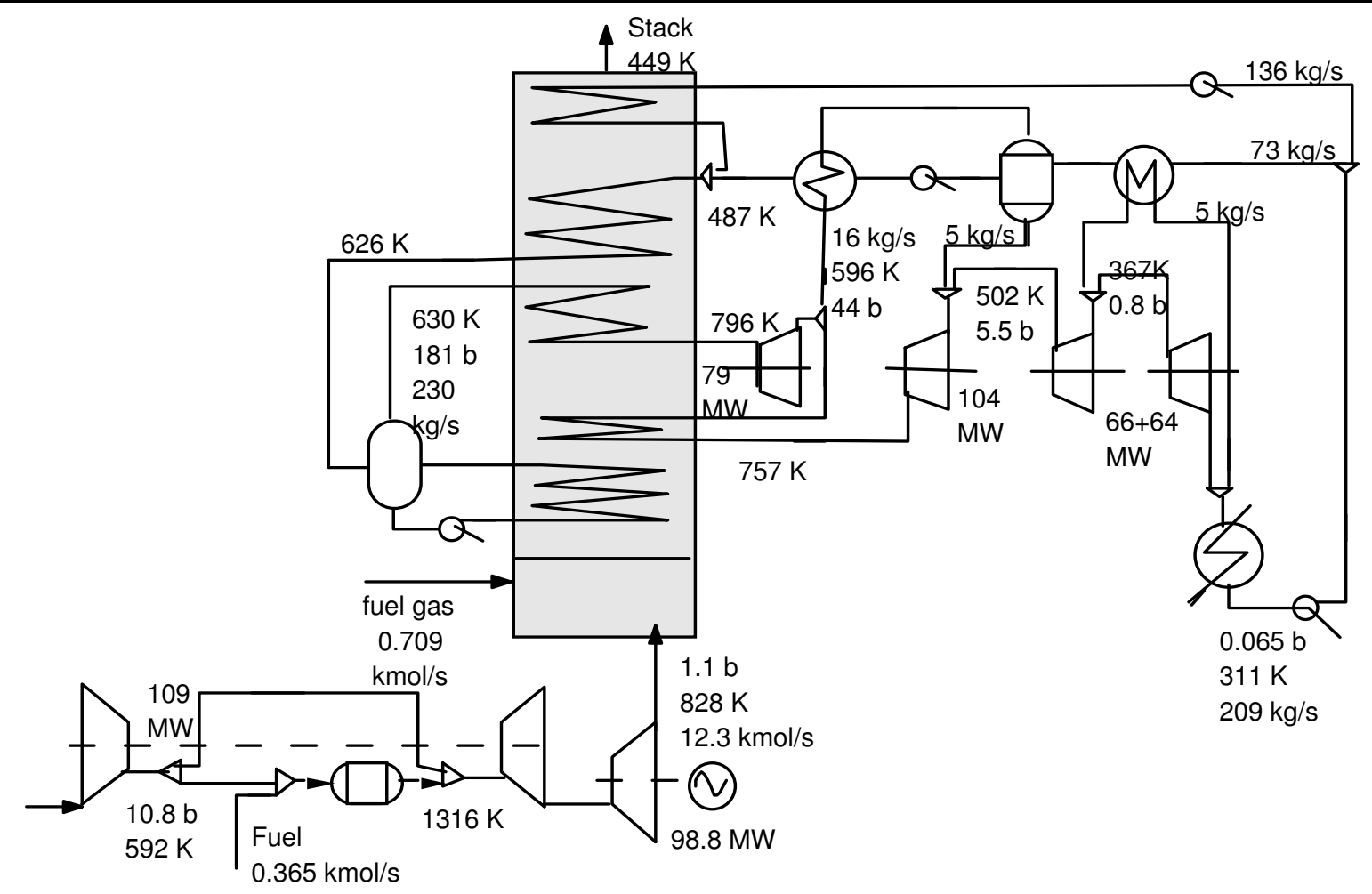

Figure 3 : topping the Rankine cycle with a gas turbine

been performed by holding the pressure profile constant, and by reducing the steam flow rate to keep the power generated by the lowest pressure turbine at its original value.

The gas turbine capacity has been fixed by an oxygen balance. Air and fuel gas flow rates are adjusted to keep the oxygen content in the stack gas equal to its original value. Since the gas turbine exhaust contains less oxygen than air, the ratio of flue gas to fuel has to increase. The fume flow rate is increased from 11.69 to $13.19 \mathrm{kmol} / \mathrm{s}$; the air preheat temperature raises also (outlet of gas turbine is $817 \mathrm{~K}$, compared to $637 \mathrm{~K}$ with air preheater). The adiabatic combustion temperature decreases from 2395 to $1973 \mathrm{~K}$. An energy balance around the combustion chamber and the vaporiser indicates that the fumes temperature entering the superheater decreases from 1940 to $1660 \mathrm{~K}$. This corresponds also to the average temperature in the combustion chamber. Knowing that the temperature of the vaporising steam remains the same, and that the energy transferred by radiation involves differences of terms in $\mathrm{T}^{4}$, one can estimate that the vaporiser capacity is reduced by approximately $45 \%$; a detailed calculation, beyond the scope of the simplified model used here, should be performed to redesign the vaporiser, taking also into account that the expected decrease in steam production (from 272 to $230 \mathrm{~kg} / \mathrm{s}$ ) brings some compensation.

The operating conditions and capacity of all heat exchangers in the convection section need also to be checked. The larger fume flow rate should enhance the heat transfer at the cost of increased pressure drop, and the gas turbine exhaust pressure has thus been set above atmospheric pressure.

Table 1 summarises the result to be expected from such a process modification. Net power from the gas turbine is $99 \mathrm{MW}$, but limitations in the steam flow rate reduce the power from the steam turbines by $32 \mathrm{MW}$. Thus the net capacity increase is $66 \mathrm{MW}$ or $19.5 \%$. Fuel usage increases by $11.9 \%$, and thus the plant exergy efficiency raises from 40 . to $42.8 \%$ 
However the plant modifications are complex : air preheater has to be replaced by a new economiser (in case of regenerative preheater, it cannot be reused), which requires significant work and a long shut down of the power plant (8 months according to Kotschenreuther (1994)). The heat exchangers used to preheat feed water with bleed steam become over designed, which may lead to operation problems. The turbine operating conditions are also modified, which may require retrofit of the machines. The investment needed for such a revamp is lower than for building a new facility with the same additional capacity; however the long shut down period needed for the modification makes this scheme unattractive.

\section{Repowering a Rankine cycle by topping with a partial oxidation gas turbine}

Another alternative can be proposed, based on partial oxidation of the fuel (Ribesse 1971 and 1991). In conventional gas turbines, the major portion of air is added to dilute the combustion products, avoiding too high a temperature, but it must nevertheless be compressed and expanded. These operations are irreversible processes, and introduce losses proportional to the total gas flow rate. Another way to avoid high temperatures is to react the fuel with air below stoichiometric proportions. Figure 4 shows how the adiabatic combustion temperature of gas varies with the air to gas ratio, assuming chemical equilibrium is achieved after reaction.

The components of a partial oxidation gas turbine are shown in figure 5. An aeroderivative gas turbine is used to generate the high temperature pressurised stream containing oxygen. This oxidising gas is mixed with the fuel and some steam; it reacts in the partial oxidation reactor in presence of a solid catalyst. The reactor exhaust is a high temperature gas, rich in $\mathrm{CO}$ and $\mathrm{H}_{2}$. The stoichiometry of the reaction is such that the molar flow rate increases

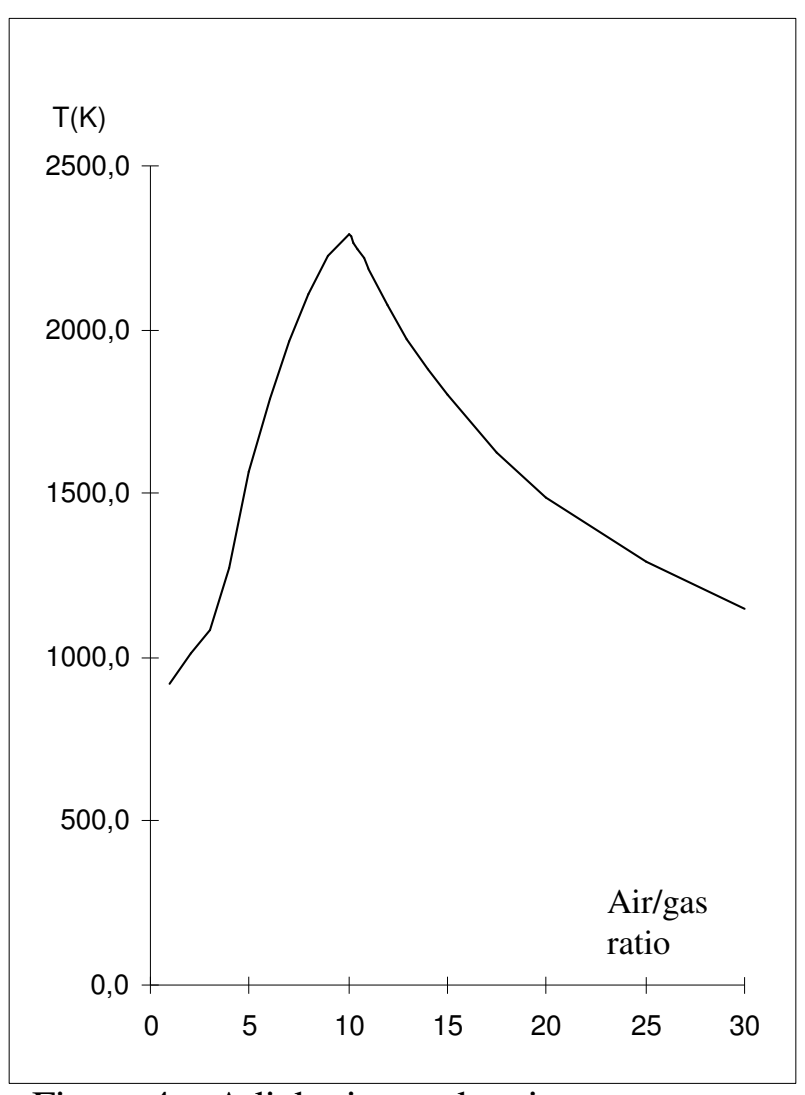

Figure 4: Adiabatic combustion temperature vs. air/gas ratio

during reaction. The air/fuel ratio is adjusted to limit the temperature of the reaction product,

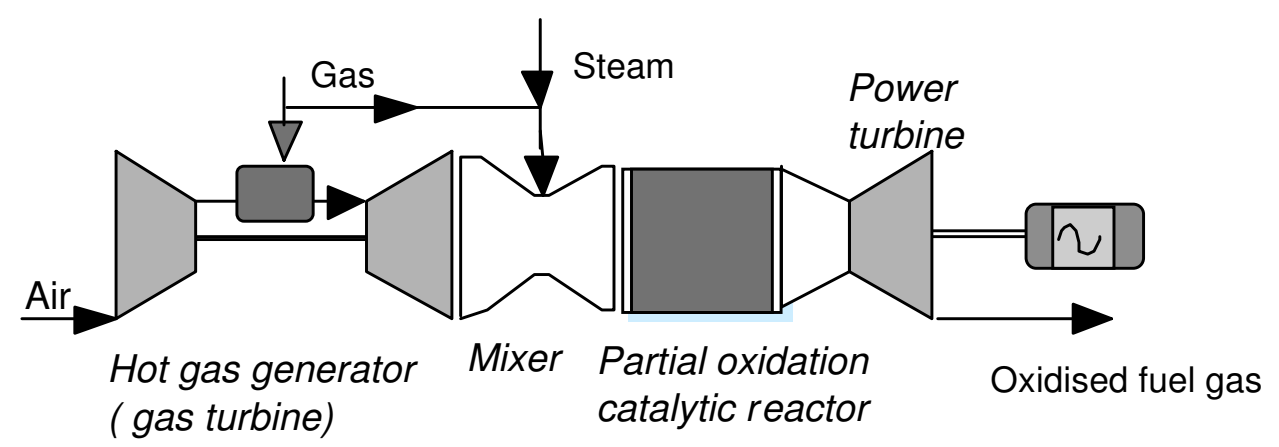

Figure 5: A partial oxidation gas turbine

Applied Thermal Engineering MS 768
A comparison of advanced thermal cycles suitable for upgrading existing power plants 


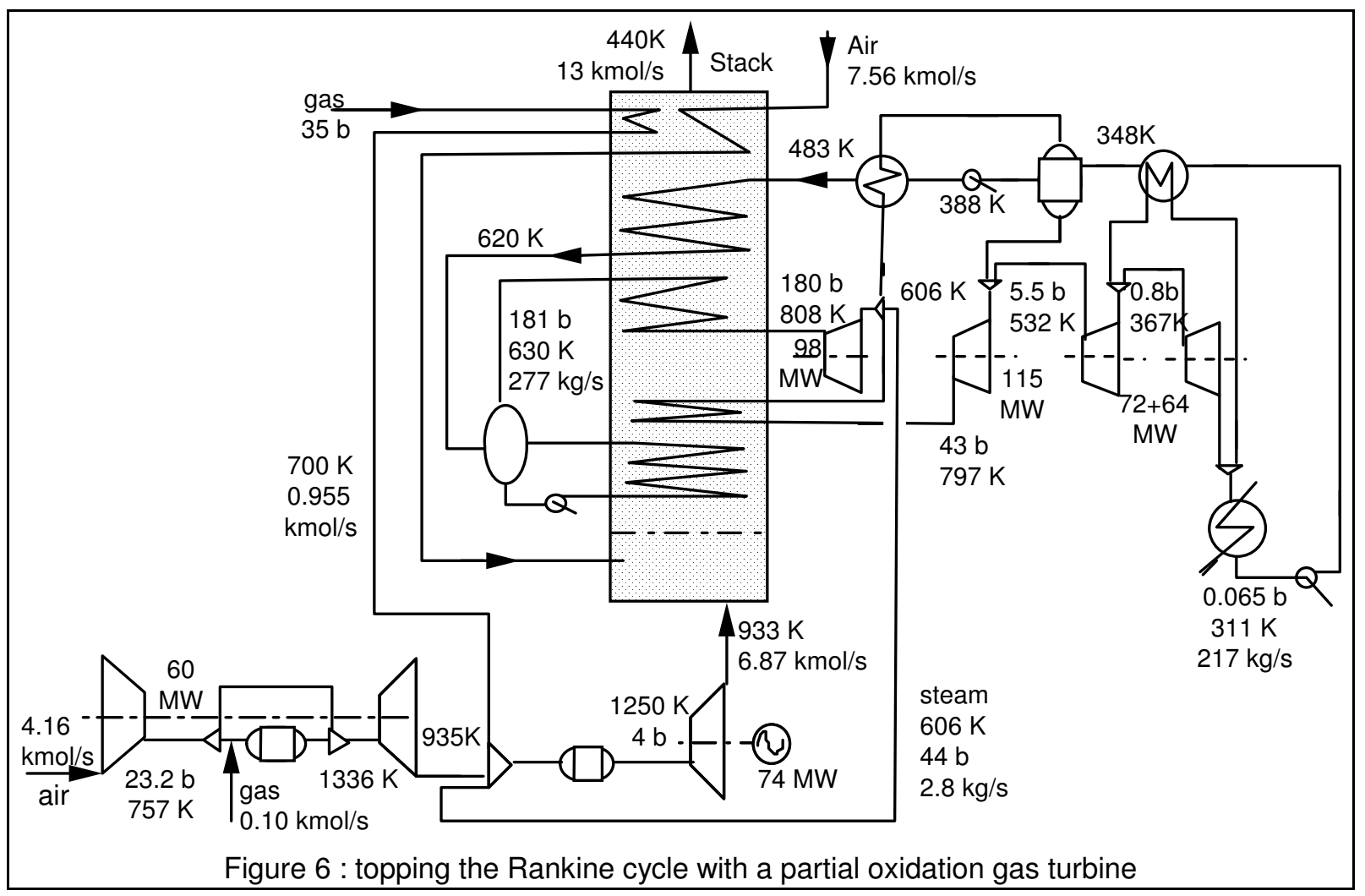

which is expanded in a second turbine and produces useful power. Finally, the turbine exhaust gas is used as fuel in a conventional steam generator.

A much lower amount of air is needed, and the gas turbine exhaust contains $\mathrm{CO}, \mathrm{H}_{2}$ and some unburned fuel. Some compression power is saved, since the molar flow rate of the exhaust gas is significantly higher than the air flow rate, which is not the case for a standard gas turbine.

The flowsheet of a process combining a conventional Rankine cycle with a partial oxidation gas turbine is illustrated in figure 6.

We note that the gas turbine needed to implement the partial oxidation system is smaller than the one needed for a topping cycle : air flow rate is reduced from 11.9 to $4.2 \mathrm{kmol} / \mathrm{s}$. The modified process has been modelled assuming that an aeroderivative gas turbine was used to generate the hot compressed air needed for the partial oxidation reactor. Pressure ratio and turbine inlet temperature of the first expansion stage match those found in commercially available machines. In the previous case, the power required was beyond the range of currently available aeroderivative engines.

Compared to the previous case, compression power is reduced from 109 to $60 \mathrm{MW}$ (even if the compression ratio has been raised from 10 to 23). The ratio of useful work to compression work is 1.23 for the partial oxidation system, compared to 0.9 for the gas turbine. The air and gas flow rate have been adjusted to provide the steam generator with the required amount of fuel gas. Oxygen content in the fumes is similar to the base case value. In practice, in case no machine matching the required duty can be found in the supplier catalogue, a smaller gas turbine may be selected and the missing fuel can be replaced by natural gas.

Compared to natural gas, the oxidised fuel gas has a lower calorific value, and it must be supplied in larger amount. In the model, the oxygen content of the fumes is kept to the same value as for the base case. Since part of the combustion air comes through the gas turbine, the load of the air preheater is decreased : fresh air flow rate to be preheated drops from 10.68 to $7.56 \mathrm{kmol} / \mathrm{s}$. This leaves energy to preheat the natural gas to be fed to the partial oxidation reactor. Even so, heat recovery from the fumes is not complete, and stack temperature raises 
to $440 \mathrm{~K}$. Steam to be injected in the reactor can be obtained from the high pressure turbine bleed.

Since the fuel gas has a lower calorific value, combustion temperature is lower than in the reference case. This is somewhat compensated by a higher preheat air temperature, and the fume temperature at the superheater inlet is only decreased by $50^{\circ}$ (from 1940 to $1890 \mathrm{~K}$ ). Using the same reasoning as for the previous case, we estimate that the vaporiser capacity is not reduced by more than $10 \%$. For all heat exchangers in the convection section, heat exchange should be improved since the fume flow rate is $10 \%$ higher than in the base case (13 kmol/s compared to 11.7).

The operating conditions of the steam system are less perturbed than in the previous case. The bleed flow rate has been kept constant, as well as the pressure profile in the turboset. Thus the only significant process modifications are the addition of the gas preheater and the redirection of a small part of the high-pressure steam bleed to feed the oxidation reactor. Gas burners must also be adapted to the modified fuel : flow rate is larger and temperature is higher. Table 1 shows what can be expected from such a process modification : the power delivered by the steam turbines remains unchanged, and the expansion of the oxidation reactor effluent allows to recover $74 \mathrm{MW}(+22.2 \%)$. Exergy content of the additional fuel gas is $117 \mathrm{MW}(+13.8 \%)$.

The overall exergy efficiency of the cycle is raised to 0.431 . While this is still below what can be achieved with a new combined cycle, whose structure is optimised and whose equipment is designed accordingly, the addition of a partial oxidation stage to an existing power plant appears to be a sensible way to improve both its efficiency and production at a moderate investment cost. Furthermore, since combustion temperature is lower than in the reference steam generator, this has a favourable impact on emission of pollutants (NOx), that can be kept easily below existing norms.

Table 1 : shaft power distribution and exergy efficiency Partial oxidation vs. standard gas turbine and base case

\begin{tabular}{|l|r|r|r|}
\hline & \multicolumn{1}{|c|}{$\begin{array}{r}\text { reference } \\
\text { cycle }\end{array}$} & $\begin{array}{r}\text { topping with } \\
\text { gas turbine }\end{array}$ & $\begin{array}{c}\text { topping with } \\
\text { partial } \\
\text { oxidation }\end{array}$ \\
\hline Gas turbine, net power (kW) & & 98856 & 73941 \\
\hline HP steam turbine (kW) & 96661 & 79351 & 97907 \\
\hline IP steam turbine (kW) & 115020 & 104380 & 114970 \\
\hline LP1 steam turbine (kW) & 71623 & 65749 & 71712 \\
\hline LP2 steam turbine (kW) & 63724 & 63759 & 64377 \\
\hline Pumps, power required (kW) & -7055 & -5836 & -7079 \\
\hline Net useful power (kW) & 339973 & 406259 & 415828 \\
\hline Exergy of NG for gas turbine (kW) & & 322840 & 91729 \\
\hline $\begin{array}{l}\text { Exergy of NG for steam gen. } \\
\text { (kW) }\end{array}$ & 848630 & 626640 & 874000 \\
\hline Total exergy of NG (kW) & 848630 & 949480 & 965729 \\
\hline Exergy efficiency & 0.400 & 0.428 & 0.431 \\
\hline $\begin{array}{l}\text { Thermal efficiency } \\
\text { (based on fuel LHV) }\end{array}$ & 0.419 & 0.448 & 0.451 \\
\hline
\end{tabular}

\section{Exergy efficiency}

Table 2 shows where the exergy losses occur. It allows to compare the factor that influences the exergy efficiency of both processes.

Comparing absolute figure, we notice that exergy loss in heat exchangers is similar for the reference cycle and for the partial oxidation modification. Since the steam system is almost the same in both cases, one can conclude that the modification does not degrade 
significantly the heat exchange train. The losses in heat exchangers appear lower when using a gas turbine; however, this is explained when we consider the relative power generated by the steam system (308 MW vs. $340 \mathrm{MW}$ ). A lower power is generated using the same heat exchanger area, and this justifies lower irreversible transmission losses.

Stack losses are higher in both modified plants : the heat exchanger network has not been optimised.

The most significant remark deals with the losses due to reaction irreversibility : they are reduced with the partial oxidation scheme. In fact, some of the reactions involved in the partial oxidation are reversible; alternating heat release by stepwise oxidation with work production seems to improve the exergy efficiency of the process. Higher yields can be expected in systems that could be designed from scratch and optimised to carry out this reaction scheme. We estimate that power production could be increased by $5-7 \%$ if heat exchangers are redesigned and if limitations on steam flow rate in turbines are relaxed.

Table 2 : exergy balances,

Partial oxidation vs. standard gas turbine and base case

\begin{tabular}{|r|r|r|r|r|r|r|}
\hline & \multicolumn{2}{|c|}{ Reference cycle } & \multicolumn{2}{c|}{$\begin{array}{c}\text { topping with } \\
\text { gas turbine }\end{array}$} & \multicolumn{2}{c|}{$\begin{array}{c}\text { topping with } \\
\text { partial oxidation }\end{array}$} \\
\hline Exergy of total fuel $(\mathrm{kW})$ & 848630 & $100.00 \%$ & 949480 & $100.00 \%$ & 965729 & $100.00 \%$ \\
\hline Lost to stack & 24036 & $2.83 \%$ & 39040 & $4.11 \%$ & 36413 & $3.77 \%$ \\
\hline Lost to condenser & 22399 & $2.64 \%$ & 22789 & $2.40 \%$ & 23184 & $2.40 \%$ \\
\hline Net power & 339973 & $40.06 \%$ & 406259 & $42.79 \%$ & 415828 & $43.06 \%$ \\
\hline Reaction irreversibility & 195490 & $23.04 \%$ & 242382 & $25.53 \%$ & 198019 & $20.50 \%$ \\
\hline Mixing irreversibility & 5363 & $0.63 \%$ & 10267 & $1.08 \%$ & 15281 & $1.58 \%$ \\
\hline Loss in pumps and compressors & 1300 & $0.15 \%$ & 6937 & $0.73 \%$ & 5139 & $0.53 \%$ \\
\hline Loss in turbines & 30724 & $3.62 \%$ & 39480 & $4.16 \%$ & 41247 & $4.27 \%$ \\
\hline Loss in heat exchangers & 229350 & $27.03 \%$ & 182329 & $19.20 \%$ & 230618 & $23.88 \%$ \\
\hline
\end{tabular}

\section{Conclusions}

Repowering an existing steam cycle either by topping with a gas turbine or by using a partial oxidation reactor appear both to be alternatives that deserve a closer look. The preliminary study described here provides order of magnitude of the potential for extra power generation, and indications on the bottlenecks and the technological constraints. Any detailed analysis should be based on existing machines that can be offered by suppliers, and take into account their characteristics. A complete model of the existing plant, including detailed calculation of heat transfer, pressure drops and efficiency curves of the turbines must also be developed for each specific case : a general proposal for modification cannot be issued, and case by case analysis is necessary.

The partial oxidation technology for repowering an existing steam cycle relies on standard equipment available at moderate cost : aeroderivative gas turbines. Compared to topping with a conventional gas turbine, it does not require heavy modifications of the existing steam generator, since air circuits are kept the same : mainly the fuel delivery and burners must be modified. It allows a significant increase of the power generation capacity, while improving the overall cycle efficiency. Since combustion temperature is lower than for the original burner, the impact on emission of pollutants (NOx) is favourable, which eases the adaptation of the process to satisfy new pollution abatement constraints.

The partial oxidation gas turbine compares favourably with the conventional gas turbine : the compression work is a much smaller fraction of the expansion work, and the overall efficiency is thus less sensitive to performance degradation of the machines. A smaller compressor is thus needed to build a system able to deliver the same useful net power.

Applied Thermal Engineering MS 768
A comparison of advanced thermal cycles suitable for upgrading existing power plants
Page 8 
Partial oxidation gas turbines could be integrated into the design of new power cycles. By combining turbomachines specifically built for such operation with optimised steam cycles, we expect to raise the cycle efficiency beyond 0.60 .

\section{References}

Belsim s.a., SIMU II users guide, Belsim, Allée des Noisetiers, 1, B-4031 Angleur Belgium, (1995)

H. Kotschenreuther, "Improvement of existing large Steam Power Plant by Conversion to combined Cycle Plant", Proceedings of International Conference on Assessment and Extension of the Residual Lifetime of Fossil-Fired Power Plants, Moscow, May 16-20 (1994)

J. Ribesse, "Cycle de turbine à gaz comportant un réacteur d'oxydation partielle catalytique de gaz naturel, son application dans des systèmes énergie-chaleur", Proceedings of 8th World Energy Conference, paper 3.1-30, Bucharest, (1971)

J. Ribesse, "The Isotherm Partial Oxidation Gas Turbine", European Journal M, 36(1) 27-32 (1991) 